\title{
Shifts in early spring wind regime in North-East Europe (1955-2007)
}

\author{
S. Keevallik ${ }^{1}$ and T. Soomere ${ }^{2}$ \\ ${ }^{1}$ Marine Systems Institute at Tallinn University of Technology, Akadeemia tee 21, 12618, Estonia \\ ${ }^{2}$ Centre for Nonlinear Studies, Institute of Cybernetics at Tallinn University of Technology, Akadeemia tee 21, 12618, Estonia
}

Received: 31 January 2008 - Published in Clim. Past Discuss.: 4 March 2008

Revised: 2 June 2008 - Accepted: 4 July 2008 - Published: 4 August 2008

\begin{abstract}
Changes to the winter-to-spring switch-time of the upper air flow regime at the 850 and $500 \mathrm{hPa}$ levels over the north-eastern Baltic Sea are analyzed based on a data set extending from 1955 to 2007. The long-term variation of the air flow in early spring (March) exhibits multiple regime shifts. The shifts are extracted by means of a vector analysis of the monthly mean air flow and using statistical shift detection technology. In the middle of the 1960s the average air flow turned from NW (WNW) to W (WSW) at the $500(850) \mathrm{hPa}$ level. The original regime was restored in the mid-1990s. The regime shifts in the average air flow in March can be interpreted as changes in the transition time from winter to summer circulation type.
\end{abstract}

\section{Introduction}

There is numerous evidence indicating the gradual change of the climate of the entire Baltic Sea region, such as an annual warming trend of $0.08^{\circ} \mathrm{C} /$ decade over the period $1871-$ 2004 and an increase in precipitation over the latter part of the 20th century (BACC, 2008). Most of the relevant analysis has been concentrated on extracting linear trends in local meteorological parameters. A decrease in snow cover during the second half of the winter (Tooming and Kadaja, 2000), an increase in the amount of low clouds in March (Keevallik and Russak, 2001), warming tendencies in late winter and spring (Jaagus, 2006; Keevallik, 2003a), and decreases in the duration of ice cover (Sooäär and Jaagus, 2007), among other things, have been noticed in Estonia.

Different from many other areas that exhibit, for example, monsoon-type or El Niño-type atmospheric circulation, the climate of northern Europe is highly variable both sea-

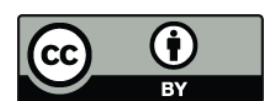

Correspondence to: $\mathrm{T}$. Soomere (soomere@cs.ioc.ee) sonally and inter-annually (BACC, 2008). The characters of the seasons and their starting dates are rather variable in the entire North Sea and Baltic Sea region. Owing to this ambiguity and the presence of several (astronomical, meteorological, and phenological) criteria to mark the beginning of a season, interpretation of the above-mentioned trends is frequently vague.

Some systematic behaviour of the climate system in the area in question, however, does no doubt exist. An important set of evidence of climate change can be extracted from changes in air circulation patterns that are one of the key components of the local weather system and the changes to which serve as generic indicators of climate changes and shifts. A number of large-scale circulation and sea level pressure patterns explaining the variability of weather over northern Estonia, such as the North Atlantic Oscillation (NAO), the Scandinavia pattern, and the East Atlantic-West Russia pattern have been identified in the scientific literature (Barnston and Livezey, 1985). A complementary set of similar structures form large-scale weather patterns - Grosswetterlagen (Gerstengarbe and Werner, 2005). A comprehensive analysis of the connections between trends in various climatic variables in Estonia and seven Northern Hemisphere teleconnection indices (including the classic NAO and Arctic oscillation indices) and frequency of circulation forms according to the Vangenheim-Girs classification has been performed in (Jaagus, 2006). The changes listed above and discussed by Jaagus (2006) frequently stem from the changes in the atmospheric circulation. This link, however, is more general. For example, the persistence of the circulation patterns is directly linked to surface air temperature anomalies (Kysely, 2007) and apparently with the occurrence of other extreme weather events.

The analysis of the changes to large-scale circulation patterns is usually made separately for the winter and summer seasons (e.g. Kysely and Huth, 2006). In the North European boreal environment these seasons exhibit completely

Published by Copernicus Publications on behalf of the European Geosciences Union. 


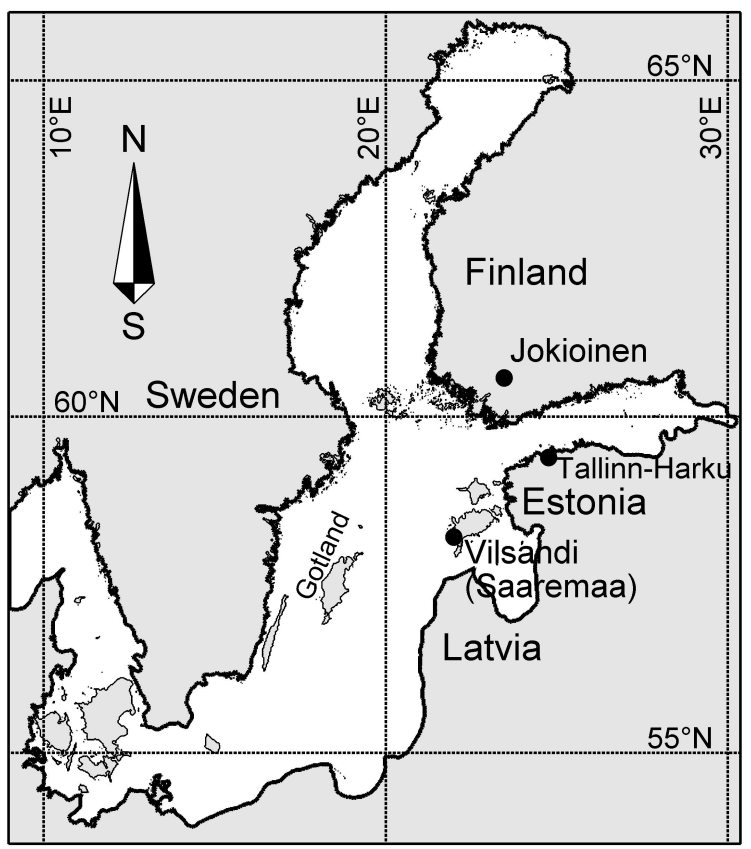

Fig. 1. Location scheme of the Baltic Sea, showing Tallinn-Harku Aerological Station, Jokioinen Observatory, and the Island of Vilsandi.

different circulation patterns and air flow properties. For example, much of the increase of the annual wind speed over the Baltic at $850 \mathrm{hPa}$ over the period of 1953-1999 has occurred during the winter season. Also, the above changes in meteorological parameters mostly characterize the late winter and spring. The changes have nontrivial spatial patterns even in relatively small regions; for example, the changes of the wind speed at the $850 \mathrm{hPa}$ level are most pronounced in the southern Baltic (Pryor and Barthelmie, 2003).

It is therefore extremely important to correctly separate the start and end of different seasons: the direct calendar-based approach may easily lead to overlooking the changes and/or to contradictory results. A primary indicator of the changes of seasons is the relevant switch of the circulation patterns. It can be identified from secondary parameters such as cloudiness, temperature etc. As these parameters frequently are strongly affected by local conditions, changes in the overall air flow serve as a more adequate pointer.

An appropriate data set for identifying the time of switch between the winter and summer circulation types is the data series of upper air winds. In this paper we address the potential changes of the switch-time of the air flow regime over the north-eastern Baltic Sea based on a time series of upper air winds extending from 1955 to 2007. The data provides novel information that could not be extracted from shorter time series. The long-term variation of the air flow does not follow simple linear trends. Instead, it exhibits clearly defined regime shifts of the air flow that have occurred more than once during the period in question. The shifts become evident from a simple vector analysis of the monthly mean air flow and are clearly visible from the statistical shift detection technology of Rodionov (2004).

\section{Data}

We use the speed and direction of upper air winds registered at Tallinn Aerological Station (Fig. 1) since 1953. Some changes in its operation and the equipment used may have affected the consistency of the data. The station was situated at Kose $\left(59^{\circ} 28^{\prime} \mathrm{N}, 24^{\circ} 49^{\prime} \mathrm{E}\right)$ from 1953 to 1977 and was moved to Harku $\left(59^{\circ} 24^{\prime} \mathrm{N}, 24^{\circ} 36^{\prime} \mathrm{E}\right.$, approximately $10 \mathrm{~km}$ to the West of its original location) in 1977. Manually operated A-22 radiosondes used in 1953-1977 were replaced by devices PK3-5 and MAP3-2 (manufactured in the former USSR) from August 1977 to May 1986 and from June 1986 to 1992, respectively. Since 1993 GPS-based DiGi Cora sondes from Vaisala are used. Soundings have been carried out four times a day from 1977 to 1992 and only at 00:00 GMT since then.

The sites have comparable openness and are located at the same distance from the City of Tallinn and from the sea coast. As the difference between the sites is not very large, one can expect that the shift of the station did not introduce any substantial inhomogeneity into the measurements of the upper air flow. The homogeneity of the time series was examined in (Keevallik and Rajasalu, 2001; Keevallik, 2003a) with the use of several tests, including the standard normal homogeneity test against data from Jokioinen Observatory (Fig. 1). No significant breaks were found and the data series may be considered as homogeneous. In order to eliminate the potential influence of several measurements a day, only midnight data (that cover the entire period 1953-2007) are considered below. As this time series has several gaps, only the months with at least 16 midnight soundings are taken into account.

Variations of the upper wind properties not necessarily become evident in surface wind data from inland stations. Winds over the sea surface, however, are thought to well reflect the free flow properties. Unfortunately, wind properties in the vicinity of Tallinn are substantially affected by the presence of land and/or contain significant inhomogeneities (Keevallik, 2003b; Soomere and Keevallik, 2003). The closest station well reflecting marine wind properties (Soomere and Keevallik, 2001, 2003) is located at the Island of Vilsandi $\left(58^{\circ} 23^{\prime} \mathrm{N}, 21^{\circ} 49^{\prime}\right)$, a small island at the eastern border of the northern Baltic Proper. The observation site at Vilsandi is located about $120 \mathrm{~m}$ from the coastline on a small limestone plateau, about $5 \mathrm{~m}$ above the mean water level, and is completely open to dominant wind directions from SW to NNW. The terrain around the station is levelled and covered with grass, and hosts only a lighthouse and a small building of the meteorological station. Forest of a moderate height is located about $300 \mathrm{~m}$ eastwards from the measurement site. The distance between Vilsandi and Harku is approximately $200 \mathrm{~km}$, 
i.e., considerably less than the typical size of free-flow circulation cells in this area.

Although wind measurements were started at Vilsandi as early as 1865 , changes in measurement equipment and routine have affected the data homogeneity. It is generally accepted that data before 1966 should not be used together with the later data for trend analysis (Keevallik et al., 2007). Thus, from eight routine recordings a day of wind data at Vilsandi, the midnight (00:00 GMT) data from 1966 to 2005 were selected to compare the results of sampling of the upper air flow with simultaneous surface wind measurements.

\section{Average air flow in the free atmosphere}

For our purposes, the most convenient property is the average air flow during intervals considerably larger than the duration of influence of a particular circulation cell at the measurement site. This property combines wind speed and direction, and is equivalent to a combination of the analysis of any two wind velocity components. Below, we use the classical wind velocity components $(u, v)$, calculated from traditionally measured wind speed and direction. Here $u$ is the zonal wind component, positive to the East, and $v$ is the meridional wind component, positive to the North. The results of the analysis are compared with the long-term changes in wind speed, which is another variable that is frequently looked at in the analysis of the average air flow, and which may also indicate changes in large-scale circulation.

The annual course of the upper air flow above Estonia is typical for north-eastern Europe up to the polar front. Wind speed is relatively large during the autumn season (OctoberJanuary), decreases considerably during the late winter and spring, and has a clearly defined minimum in mid-summer (Fig. 2). A large part of this variation is caused by changes in the intensity of the zonal flow component. The properties of local weather, however, reveal relatively weak dependence on the wind speed and are much more strongly determined by the direction of the flow. Autumn and winter weather is attributed to a northerly air flow whereas spring and summer conditions are brought to Estonia by a southerly air flow. The switching between the two types of flow is quite abrupt in March-April and smoother at the end of August (Fig. 2). The potential shifts of this time are decisive for many of the parameters discussed above, such as the duration of snow cover or the length of the ice season.

While the timing of the autumn switch exhibits no significant trends within the latter half-century, several intriguing changes in free flow patterns during the spring switch were recently established. Significant positive trends in the wind meridional component were detected in March for the period 1955-1995 (Keevallik, 2003a). The increase of this component was $0.10(0.16) \mathrm{m} / \mathrm{s}$ per year at the $850(500) \mathrm{hPa}$ level. Statistically significant trends of increasing velocity existed for the zonal component at $850 \mathrm{hPa}: 0.10 \mathrm{~m} / \mathrm{s}$ per year

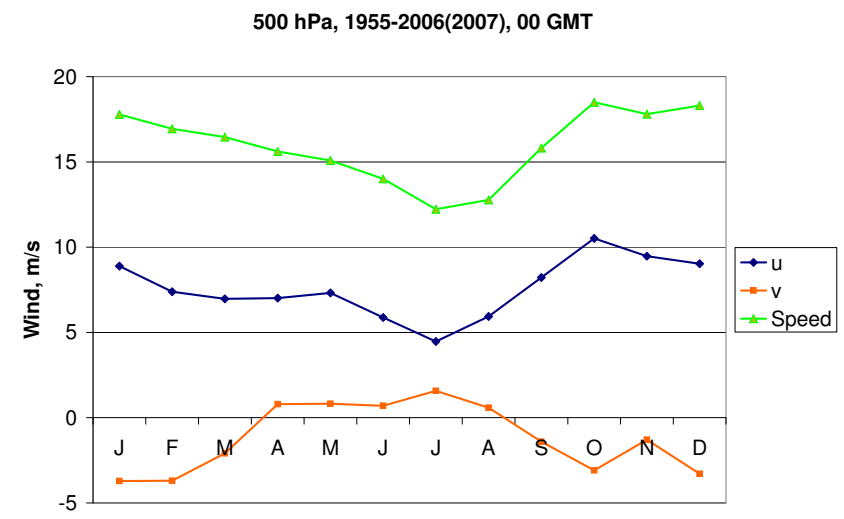

Fig. 2. Annual changes in monthly average wind speed, zonal $(u)$ and meridional $(v)$ wind velocity components at the $500 \mathrm{hPa}$ level.

in February and $0.08 \mathrm{~m} / \mathrm{s}$ per year in March (Fig. 3). There were no changes in the temporal course of the meridional wind component in February.

Extension of the time series until 2007 reveals that the parameters in question generally possess no unambiguous trends. Instead, more complex features of decadal variations become evident.

During the period 1955-2007, the zonal wind component at the $850 \mathrm{hPa}$ level still shows a significant (level 0.1) positive trend. Its formal slope is $0.051 \mathrm{~m} / \mathrm{s}$ per year in February, i.e., about a half of that between 1955 and 1995. Figure 3, however, reveals that extremely large variations of the zonal wind component occurred in February compared to its monthly mean (about 5 (7) $\mathrm{m} / \mathrm{s}$ at the 850 (500) hPa level). A total collapse of the zonal flow occurred in the mid-1980s and there were even a few years during which easterly flow predominates. The zonal flow was restored at a much more intense level at the end of the 1980s, with typical monthly mean values about twice as large as in the 1960s and the 1970s. At the turn of the century, another drastic reduction of the average zonal flow occurred.

Such sawtooth-like behaviour of the zonal wind component suggests that certain regime switches have occurred. Since there were no simultaneous changes of the meridional wind component, the switches apparently led to certain variations of the overall (incl. surface) wind speed that can be first detected from marine observations. The described features qualitatively coincide with the pattern of annual mean wave activity in the northern Baltic Sea. The annual mean wave height was relatively low in the 1980 s, increased considerably from the end of the 1980s, reaching the highest values of the last 50 years in the mid-1990, and decreased by a factor of three by the year 2005 (Broman et al., 2006; Soomere and Zaitseva, 2007).

For the newly available data from 1955-2007, neither zonal nor meridional wind component shows significant trend in March (Fig. 3). The behaviour of the meridional 

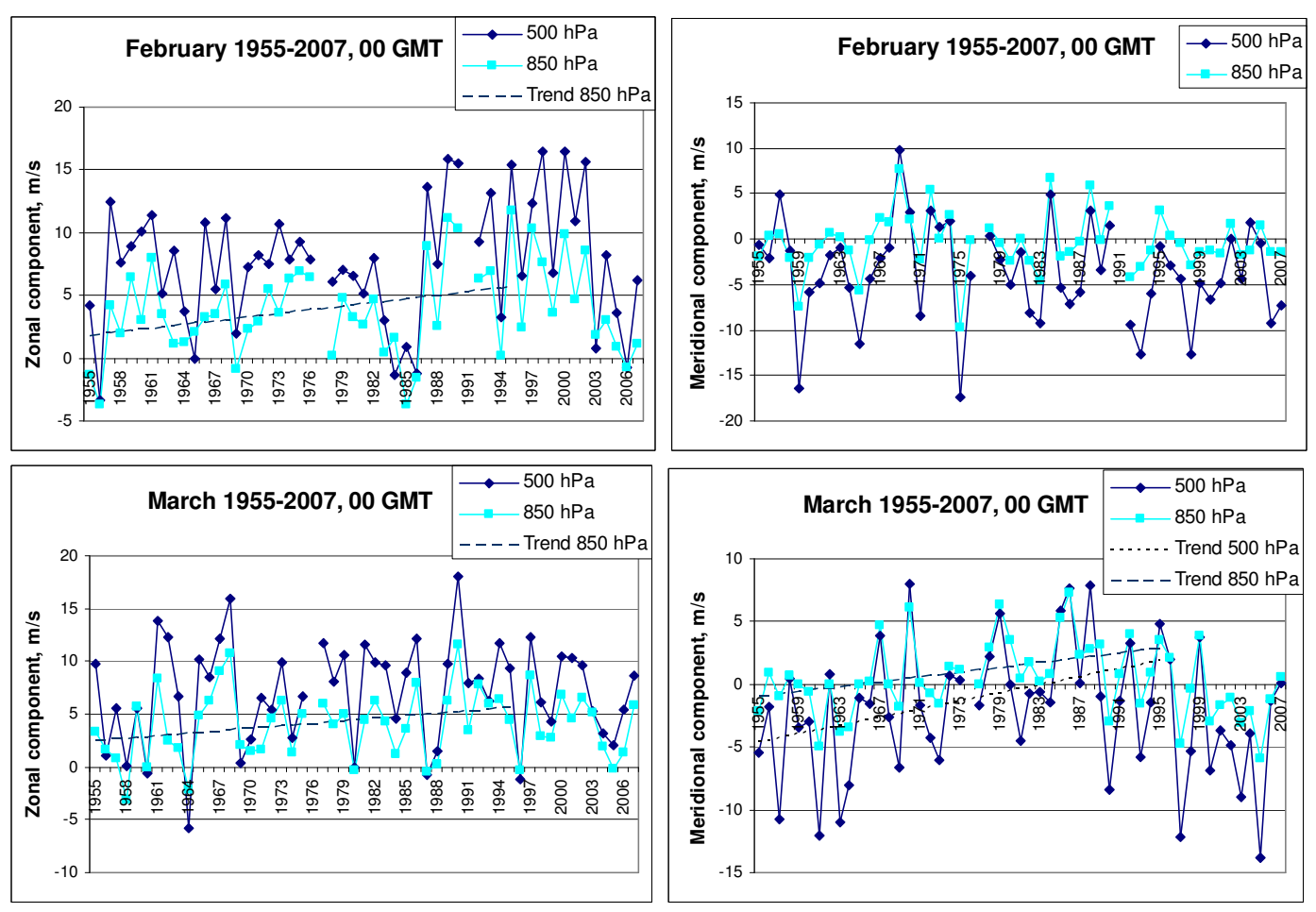

Fig. 3. Upper air wind components at two isobaric levels (500 and $850 \mathrm{hPa}$ ) over Estonia in February and March in 1955-2007. Trends (significant at least at the 0.1 level) established by Keevallik (2003a) are shown by dashed lines extending over 1955-1995.

wind component in March, however, exhibits an extremely interesting course offering several interpretations. The increasing trend (corresponding to gradual change of the direction of the mean air flow from NW to $\mathrm{W}$ ) was replaced by a decreasing trend with roughly the same slope in the mid-1980s. The overall pattern of changes may also be interpreted as evidence of a long-term quasi-periodical behaviour, with the period larger than the duration of the time series.

The above discussion of the character of the zonal flow in February leads to a perception that regime shifts in the wind system may have taken place. The existence of such shifts becomes qualitatively evident from the analysis of the decadal average air flow in March. The years when the regime changed can be roughly established from a simple vector representation of the air flow. While the mean air flow on the $500 \mathrm{hPa}$ level was from NW in 1955-1966, it was mostly from $\mathrm{W}$ over about three decades and reversed back to NW just before the turn of the millennium (Fig. 4). Although the actual years indicated in Fig. 4 have been selected visually, the overall behaviour of the air flow suggests that major shifts have occurred in the mid-1960s and in the mid-1990s.

An equivalent shift from the predominating WNW air flow at the $850 \mathrm{hPa}$ level to a WSW flow took place in the mid1960s. The reversal of the flow to the original direction occurred in the mid-1990s (Fig. 5). The magnitude of the shift in the direction is approximately the same at both levels. This feature suggests that a turn of the free flow has occurred at all heights. Although such turns do not necessarily become evident at the surface level, the average surface-level air flow at midnight at Vilsandi reveals the influence of the switch in the mid-1990s. The monthly mean surface air flow was to the NNE during 1976-1995 (Fig. 5), but turned abruptly to almost E in the mid-1990s and decreased to some extent in intensity. Unfortunately, such a comparison is not available for the Vilsandi data for the years before 1966.

\section{Regime shifts}

The above discussion suggests that at least two substantial shifts of the meridional component of the upper air flow above Estonia have occurred since the 1950s. A more exact identification of the time of the shifts is possible by means of a technique elaborated in (Rodionov 2004; Rodionov and Overland, 2005). The timings of regime shifts (Table 1) are found using cut-off length of 10 years and Huber's weight parameter of 2 (i.e., all wind component values that are less than two standard deviations have equal weights). This method reveals that at least two regime shifts have taken place in the average air flow at the $500 \mathrm{hPa}$ level in March: one in the mid-1960s and another in the mid-1990s. Additionally, the method signals the possibility of a future regime shift. Also, regime shifts in the zonal flow in February are 


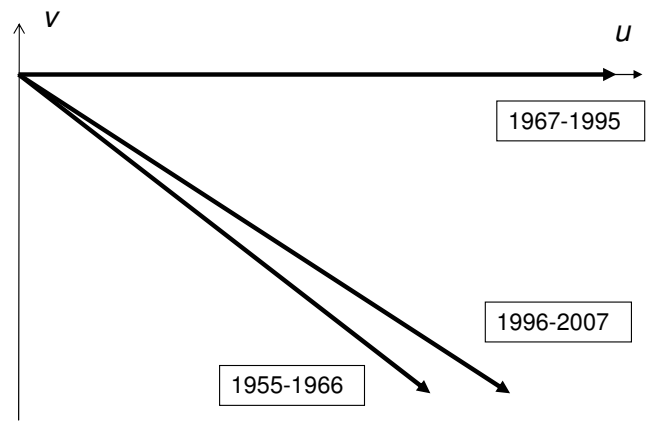

Fig. 4. Monthly average air flow at the $500 \mathrm{hPa}$ level in March during different decades. The scaling of the $u$ - and $v$-axes is equal. (a)

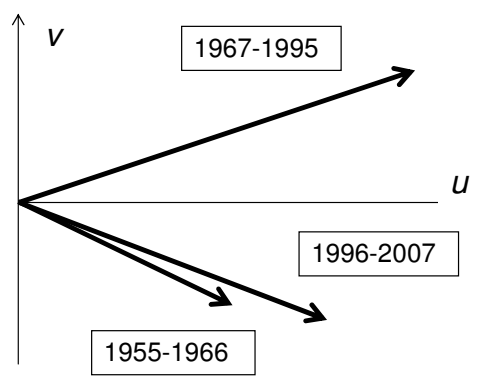

(b)

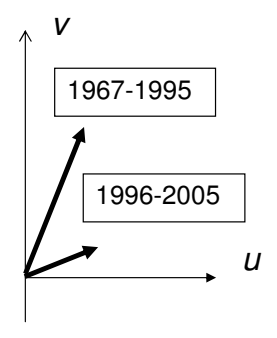

Fig. 5. Monthly average air flow at the $850 \mathrm{hPa}$ level (a) and at the surface (b) in March during different decades. The scaling of the $u$ and $v$-axes is equal.

evident in the mid-1980s (when the intensity abruptly increases) and at the beginning of the 2000s when the average zonal flow again decreases. No clear shifts in the character of the air flow occurred during other months. The described shifts are less clearly visible in surface data with only an abrupt increase of the zonal flow in February and March occurring at the end of the 1980s.

\section{Conclusion and discussion}

The annual pattern of the upper air flow over Estonia has two typical regimes: a relatively intense north-westerly flow during the autumn and winter season (September-February) and a less intense south-westerly flow during the spring and summer season (April-August). The flow transition is quite abrupt at the beginning of the summer season, but fairly smooth at its end (Fig. 2).

The key outcome of the above analysis is that the longterm variation of the transition time demonstrates neither a simple linear trend nor periodic behaviour. It exhibits clearly defined multiple regime shifts. The largest changes have occurred in March. In the middle of the 1960s the average air flow in March turned from NW to W at the $500 \mathrm{hPa}$ level. The original regime was restored in the mid-1990s. Analo-
Table 1. Timings of regime shifts in wind components and weighed averages of the regimes.

\begin{tabular}{lrr}
\hline Period & $\begin{array}{r}\text { Zonal } \\
\text { component, } \\
\mathrm{m} / \mathrm{s}\end{array}$ & $\begin{array}{r}\text { Meridional } \\
\text { component, } \\
\mathrm{m} / \mathrm{s}\end{array}$ \\
\hline (a) 500 hPa, March & & \\
$1955-1964$ & 7.03 & -5.43 \\
$1965-1996$ & 7.03 & 0.05 \\
$1997-2005$ & 7.03 & -6.20 \\
$2006-2007$ & 7.03 & -0.66 \\
& & \\
(b) 850 hPa, March & & \\
$1955-1964$ & 1.84 & -1.19 \\
$1965-1966$ & 4.47 & -1.19 \\
$1967-1996$ & 4.47 & 1.83 \\
1997-2006 & 4.47 & -1.92 \\
& & \\
(c) 500 hPa, February & & \\
$1955-1986$ & 6.02 & -3.38 \\
$1987-2002$ & 12.14 & -3.38 \\
$2003-2005$ & 3.62 & -3.38 \\
$2006-2007$ & 3.62 & -8.24 \\
\hline
\end{tabular}

gous changes (the turn of the air flow from WNW to WSW and back) also occurred in the air flow at the $850 \mathrm{hPa}$ level and at the surface.

The regime shifts in the average air flow in March can be interpreted as changes in the transition time from winter to summer circulation type. March was characterized by winter circulation in the 1950s. During about 30 years from the mid-1960s the summer circulation started several weeks earlier. From the mid-1990s the start of the summer circulation was again delayed to April as in the 1950s. Equivalently, it may be hypothesized that the circulation system above Estonia moved between different quasistationary states whereas the one that dominated from approximately 1966 to 1996 corresponded to clearly shorter winters. The large jump of the transition time and the persistence of all the regimes suggest that the regime switches mimic changing properties of certain large-scale processes with a small number of degrees of freedom, such as the location of the polar front and/or the nodes of the planetary wave system.

The presence of multiple shifts and the sawtooth-like behaviour of the zonal wind component as discussed above, suggests that the climate system (either its gradual changes or its natural variability) comprises considerable quasi-periodic variability with time scales of about $20-30$ years. Such longterm variability has been recently identified for the northern Baltic Sea wave fields. Similar regime shifts may be reflected in associated climatological parameters such as variations in the level of large lakes in northern Europe (Järvet, 2004). They are apparently accompanied by changes in 
surface temperature, precipitation and low cloudiness. The analysis of such changes is currently in progress.

Although the nature of identified shifts cannot be unambiguously recognized based on the existing data set, their presence may shed additional light on the course of climate changes in northern Europe and provide evidence that cannot be extracted from more generalised variables. For example, two variations of the NAO index are defined as the difference in normalized pressure between SW Iceland and Ponta Delgada or Gibraltar. The correlation coefficient between these indices during 1955-2003 is 0.741 and neither of them shows regime shifts similar to those detected in the air flow over Estonia. This feature is not totally unexpected, because regime shifts in air flow are mainly due to changes in the meridional flow component.

The identified regime changes are consistent with the sharp increase in the persistence of circulation patterns in all seasons from the 1970s to the late 1980s (Kysely and Domonkos, 2006). Our analysis, however, sheds more light to the "outlier" period at the very end of the 20th century. It is highly probable that the air flow in spring has simply reversed to the pattern that dominated in the middle of the 20th century. One cannot judge, however, whether this regime is equivalent to that of the 1950s. The reverse combined with a considerable increase in the persistence of circulation types may be one of the reasons for the increase in climatic extremes, in particular, of wind-induced wave and storm surge extremes in the Baltic Sea basin (Suursaar et al., 2006; Soomere et al., 2008) that were seldom evident before the 1960s but which have been frequently observed in Europe during recent years (Kysely and Huth, 2006).

Acknowledgements. We are grateful to Kai Loitjärv for digitizing aerological data for the period of 1999-2007 from the archive of the Estonian Meteorological and Hydrological Institute. The research was supported by Estonian Science Foundation, Grant 7413.

Edited by: H. Dolman

\section{References}

The BACC Author Team: Assessment of Climate Change for the Baltic Sea Basin, Springer, 2008.

Barnston, A. G. and Livezey, R. E.: Classification, seasonality and persistence of low-frequency atmospheric circulation patterns, Mon. Wea. Rev., 115, 1083-1126, 1987.

Broman, B., Hammarklint, T., Rannat, K., Soomere, T., and Valdmann, A.: Trends and extremes of wave fields in the northeastern part of the Baltic Proper, Oceanologia, 48(S), 165-184, 2006.

Gerstengarbe, F.-M. and Werner, P. C.: Katalog der Grosswetterlagen Europas (1881-2004) nach Paul Hess and Helmuth Brezovsky, 6, verbesserte und ergänzte Auflage, PIK Report No 100, 2005.
Jaagus, J.: Climatic changes in Estonia during the second half of the 20th century in relationship with changes in large-scale atmospheric circulation, Theor. Appl. Climatol., 83, 77-88, 2006.

Järvet, A.: Influence of hydrological factors and human impact on the ecological state of shallow Lake Võrtsjärv in Estonia, Dissertationes Geographicae Universitatis Tartuensis, Tartu, Estonia, 2004.

Keevallik, S.: Changes in spring weather conditions and atmospheric circulation in Estonia (1955-1995), Int. J. Climatol., 23, 263-270, 2003a.

Keevallik, S.: Possibilities of reconstruction of the wind regime on Tallinn Bay, Proc. Estonian Acad. Sci. Eng., 9, 209-219, 2003b.

Keevallik, S. and Rajasalu, R.: Winds on the $500 \mathrm{hPa}$ isobaric level over Estonia (1953-1998), Phys. Chem. Earth PTB, 26, 425429, 2001.

Keevallik, S. and Russak, V.: Changes in the amount of low clouds in Estonia (1955-1995), Int. J. Climatol., 21, 389-397, 2001.

Keevallik, S., Soomere, T., Pärg, R., and Žukova, V.: Outlook for wind measurement at Estonian automatic weather stations, Proc. Estonian Acad. Sci. Eng., 13, 234-251, 2007.

Kysely, J.: Implications of enhanced persistence of atmospheric circulation for the occurrence and severity of temperature extremes, Int. J. Climatol., 27, 689-695, 2007.

Kysely, J. and Domonkos, P.: Recent increase in persistence of atmospheric circulation over Europe: Comparison with long-term variations since 1881, Int. J. Climatol., 26, 461-483, 2006.

Kysely, J. and Huth, R.: Changes in atmospheric circulation over Europe detected by objective and subjective methods, Theor. Appl. Climatol., 85, 19-36, 2006.

Pryor, S. C. and Barthelmie, R. J.: Long-term trends in near-surface flow over the Baltic, Int. J. Climatol., 23, 271-289, 2003.

Rodionov, S. N.: A sequential algorithm for testing climate regime shifts, Geophys. Res. Lett., 31, L09204, doi:10.1029/2004GL019448, 2004.

Rodionov, S. and Overland, J. E.: Application of a sequential regime shift detection method to the Bering Sea ecosystem, ICES J. Mar. Sci., 62, 328-332, 2005.

Soomere, T. and Keevallik, S.: Anisotropy of moderate and strong winds in the Baltic Proper, Proc. Estonian Acad. Sci. Eng., 7, 35-49, 2001.

Soomere, T. and Keevallik, S.: Directional and extreme wind properties in the Gulf of Finland, Proc. Estonian Acad. Sci. Eng., 9, 73-90, 2003.

Soomere, T. and Zaitseva, I.: Estimates of wave climate in the northern Baltic Proper derived from visual wave observations at Vilsandi, Proc. Estonian Acad. Sci. Eng., 13, 48-64, 2007.

Soomere, T., Behrens, A., Tuomi, L., and Nielsen, J. W.: Wave conditions in the Baltic Proper and in the Gulf of Finland during windstorm Gudrun, Nat. Hazards Earth Syst. Sci., 8, 37-46, 2008, http://www.nat-hazards-earth-syst-sci.net/8/37/2008/.

Sooäär, J. and Jaagus, J.: Long-term variability and changes in the sea ice regime in the Baltic Sea near the Estonian coast, Proc. Estonian Acad. Sci. Eng., 13, 189-200, 2007.

Suursaar, Ü., Kullas, T., Otsmann, M, Saaremäe, I., Kuik, J., and Merilain, M.: Hurricane Gudrun and modelling its hydrodynamic consequences in the Estonian coastal waters, Boreal Env. Res., 11, 143-159, 2006.

Tooming, H. and Kadaja, J.: Snow cover and surface albedo in Estonia, Meteorol. Z., N. F. 9, 97-102, 2000. 